\title{
Aplicação da educação ambiental em escola pública de Boa Vista,
}

\section{Roraima}

\author{
Auriane da Conceição Dutra da Silva ${ }^{1 *}$, João Luiz Lopes Monteiro Neto ${ }^{2}$, Rodrigo \\ Junior Schneider ${ }^{3}$, Rayssa Natasha Barros Mafra ${ }^{4}$
}

1. Universidade Federal de Roraima, Centro de Ciências Agrárias, Campus Cauamé, CEP: 69.300-000, Boa VistaRoraima. (95) 3625-7631.

2. Universidade Federal de Roraima - Programa de Pós-Graduação em Agronomia (POSAGRO), Centro de Ciências Agrárias, Campus Cauamé, CEP: 69.300-000, Boa Vista-Roraima. joao.monteiro.neto@hotmail.com

3. Universidade Tecnológica Federal do Paraná, Campus Dois Vizinhos. Estr. p/ Boa Esperança s.n., Zona Rural, Dois Vizinhos, Paraná, CEP 85660-000. Email: s.rodrigojr@hotmail.com

4. Universidade Federal de Roraima, Centro de Ciências Agrárias, Campus Cauamé, CEP: 69.300-000, Boa VistaRoraima.natashamafra@gmail.com

*E-mail para correspondência: silvaauriane@hotmail.com

Recebido em: 01 de fevereiro de 2017. Aceito em: 13 de março de 2017. Publicado PDF em: 16 de março de 2017

\section{RESUMO}

\begin{abstract}
Aplicação da educação ambiental em escola pública de Boa Vista, Roraima. A educação ambiental se insere organicamente na educação integral e favorece o envolvimento direto dos sujeitos sociais no processo educativo. $\mathrm{O}$ trabalho foi desenvolvido na Escola de Ensino Fundamental, Boa Vista, com alunos regularmente matriculados. Incialmente foi realizada uma palestra com professores e funcionários sobre a importância e objetivos do projeto, destacando a relevância do apoio de todos para atingir as metas propostas. Todos os alunos da escola foram beneficiados com as ações do projeto, onde cada turma participou das atividades uma vez por mês. Foram ministradas palestras abordando assuntos sobre meio ambiente, instigando os alunos a reconhecer a responsabilidade ambiental de cada ser vivo. Estas foram aplicadas de forma dinâmica e cognitiva, utilizando os recursos áudio visuais disponíveis e o ambiente escolar como prática de vivência. Paralelamente foi realizada a pratica de jardinagem, dividida em: produção de mudas, construção e manutenção do jardim. Além das atividades descritas, foram aplicados questionários semi estruturados (perguntas abertas e fechadas) sobre os temas abordados nas palestras, conhecimentos empíricos e adquiridos pelos alunos. Os alunos interagiram de forma satisfatória durante as aulas, com questionamentos e relatos de vivência, participando ativamente das práticas, assim como os professores e os demais funcionários da escola que auxiliaram durante a implantação do projeto. Portanto, é notório que o projeto contribui para o ensino e aprendizagem, despertando a consciência ambiental e sustentável, cabendo ao educador buscar informações especificas e novas atividades instigantes ao aluno.
\end{abstract}

PALAVRAS CHAVE: Jardinagem; Sociedade; Sustentabilidade.

\begin{abstract}
Application of environmental education in a public school in Boa Vista, Roraima. Environmental education is integrated organically in integral education and favors the direct involvement of social subjects in the educational process. The work was developed at an Elementary School in Boa Vista municipality, with regularly enrolled students. Initially a lecture was held with teachers and staff about the importance and objectives of the project, highlighting the relevance of the support of all to achieve the proposed goals. All students at the school were benefited with the project actions, where each class participated in the activities once a month. Lectures were given addressing environmental issues, encouraging students to recognize the environmental responsibility of each living being. These were applied in a dynamic and cognitive way, using the visual audio resources available and the school environment as a living practice. In parallel, the practice of gardening was carried out, divided into: production of seedlings, construction and maintenance of the garden. In addition to the described activities, semi structured questionnaires (open and closed questions) were applied on the topics addressed in the lectures, empirical knowledge and acquired by the students. The students interacted satisfactorily during the classes, with questions and experiences, actively participating in the practices, as well as the teachers and other school officials who assisted during the implementation of the project. Therefore, it is notorious that the project contributes to teaching and learning, awakening environmental and sustainable awareness and it is up to the educator to seek specific information and new activities that stimulate the student.
\end{abstract}

KEY WORDS: Gardening; Society; Sustainability. 


\section{INTRODUÇÃO}

A busca incessante pelo aumento produtivo de indústrias e lavouras tem feito com que o ser humano cause diversos impactos ambientais negativos nas últimas décadas. Ademais as cidades crescem, na maioria das vezes, de forma rápida e desordenada, sem um planejamento adequado de ocupação, provocando muitos problemas que interferem na qualidade de vida do homem que nela habita (Silva \& Moraes 2016).

Diariamente, os meios de comunicação veiculam diversos acontecimentos que caracterizam o desequilíbrio do meio ambiente, a exemplo de enchentes, supressão de recursos naturais, queimadas, poluição e diversos problemas socioeconômicos (Andrade et al. 2012). A questão ambiental é chamada a responder a uma pluralidade de necessidades e especificidades às mudanças demográficas, às condições sociais, às mudanças epidemiológicas, centrando-se no ser humano, individual ou coletivo (Bonfim et al. 2015).

A educação ambiental é um recurso que atua de forma holística no processo da busca de conservação e preservação dos recursos naturais e a sustentabilidade, se inserindo organicamente na educação integral. O tema ganhou notoriedade com a promulgação da Lei 9.795, de 27 de abril de 1999, que instituiu a Política Nacional de Educação Ambiental e por meio desta, foi estabelecida a obrigatoriedade do ensino desta área em todos os níveis formais da educação brasileira. Essa lei precisa ser mencionada como um marco importante da história no Brasil, pois resultou de um longo processo de interlocução entre ambientalistas, educadores e governos (Brasil 1999).

Em contrapartida, é notório que os educadores ficam limitados aos conteúdos que lhes são estabelecidos, que na maioria das vezes, em função da extensa carga horária curricular, não conseguem concluí-los até o fim do ano letivo. Concomitantemente, muitos professores não se sentem na obrigação de aplicar um tema que saia dos limites didáticos estabelecidos, como os assuntos inerentes à educação ambiental. Essas constatações são de extrema importância, tornando necessária a mudança de postura educacional voltada à educação ambiental, visto que a cada dia, com a expansão populacional, há também o aumento do número de poluidores, o que justifica o fomento de tal tema no sistema educacional
(Cuba 2010; Medeiros et al. 2011).

A adoção de princípios e práticas sociais sustentáveis, sem dúvidas, favorece o envolvimento direto dos sujeitos sociais no processo educativo. Essa concepção inovadora valoriza processos de transformação socioambiental, traz a contemporaneidade para o debate da função social da escola e potencializa sua capacidade de reorganizar tempo, espaço e o ambiente escolar, mais que isso, mostra que é possível transformar as escolas em verdadeiras referências de sustentabilidade (Czapski \& Trajber 2010).

Para que a educação ambiental seja efetiva e contribua com a formação de uma cidadania pautada na sustentabilidade, toda a comunidade precisa se unir à construção de um ambiente escolar agradável, sendo assim incubadora de mudanças concretas na realidade social.

Buscou-se com esta proposta a realização de um trabalho na escola integrando aspectos que possam contribuir para o desenvolvimento sustentável, no intuito de torná-la um modelo de vivência, na qual se integram aspectos sociais, ecológicos, econômicos e culturais de forma equilibrada, proporcionando meios adequados para realização de atividade de jardinagem, visando embelezar a paisagem e garantir maior agradabilidade ao ambiente escolar (Medeiros et al. 2011).

Neste contexto, objetivou-se com este trabalho contribuir no processo de construção de cidadãos ambientalmente conscientes, atuantes e multiplicadores, buscando gerar efetivas mudanças de atitudes e assim, construir uma cadeia de ações positivas para uma sociedade mais saudável e ambientalmente correta.

\section{MATERIAL E MÉTODOS}

O projeto foi desenvolvido na Escola de Ensino Fundamental Francisca Elzika Coelho, Município de Boa Vista-RR, com alunos regularmente matriculados. Incialmente foi realizada uma palestra para sensibilizar toda equipe pedagógica sobre a importância e objetivos do projeto, destacando a relevância do apoio de todos para atingir as metas propostas.

A atividade foi dividida em: palestras, produção de mudas, construção e manutenção do jardim. Todas as 20 turmas da escola foram beneficiadas com as ações do projeto, um total 
de 600 alunos, onde cada turma participou das atividades uma vez por mês com uma hora de aula teórica e prática. O tempo total de implementação do projeto foi de 14 meses.

As palestras foram apresentadas tanto para os alunos do ensino infantil, como para os do ensino fundamental. Contudo, para os primeiros, o projeto foi passado de forma mais ilustrativa, com muitas figuras e uma linguagem mais simples, a fim de facilitar a compreensão. Para os alunos do ensino fundamental, os temas foram aplicados de forma mais abrangente, correlacionando-os com o conteúdo das matérias do ensino regular.

As palestras abordaram assuntos sobre meio ambiente, instigando os alunos a reconhecer a responsabilidade ambiental de cada ser vivo. Os temas abordados foram: ciclo de vida das plantas, água, aquecimento global, preservação ambiental, lixo, alimentação saudável e arborização.

Para preparação de implantação do jardim, foram ministradas palestras abordando assuntos sobre meio ambiente, solo, produção de mudas, nutrição, desenvolvimento de plantas e descrição básica sobre plantas ornamentais visando o levantamento e nivelamento das concepções prévias dos educandos acerca dos temas em estudo.

Estas palestras foram realizadas de forma dinâmica e cognitiva, utilizando os recursos áudio visuais disponíveis e o ambiente escolar como prática de vivência em cada atividade.

Para a produção de mudas o projeto recebeu a doação de sementes e estacas de plantas ornamentais. Foram reutilizados materiais disponíveis na escola para implantação do jardim, realizada a limpeza da área, aplicação do adubo orgânico, revolvimento do solo e a distribuição das mudas conforme delineamento proposto.

A proposta abordada foi que os alunos e funcionários produzissem e realizassem $\mathrm{o}$ manejo das mudas e manutenção do jardim, realizando atividades como irrigações diárias, limpeza de plantas invasoras, poda e adubação.

Os critérios para a localização do jardim e a escolha das plantas para sua composição foram observando fatores como: disponibilidade de luz, água, condições do solo, além da visibilidade, priorizando locais mais movimentados e locais de lazer.

Além das atividades descritas foram aplicados questionários semiestruturados (perguntas abertas e fechadas) sobre as palestras e conhecimentos empíricos e adquiridos pelos alunos.

\section{RESULTADOS E DISCUSSÃO}

Os alunos interagiram de forma satisfatória durante as aulas, com questionamentos e relatos de vivência, participando ativamente das práticas, assim como os professores e os demais funcionários da escola que auxiliaram durante a implantação do projeto. Trabalhos semelhantes como os de Costa et al. (2015) e Santos et al. (2014) descrevem o engajamento dos educandos e docentes na luta pedagógica da interdisciplinaridade e implantação de projetos como de horta na escola.

O levantamento das expectativas revelou que $100 \%$ dos estudantes possuíam consciência sobre a problemática do meio ambiente, sustentabilidade e hábitos alimentares. Destes, $53 \%$ relataram alguma vivência relacionada a impactos negativos no meio ambiente.

Quanto ao manejo do lixo, 85\% dos estudantes reconheceram que jogam ou já jogaram lixo na rua. Antes do projeto, $24,5 \%$ dos alunos afirmaram que faziam algum tipo de reciclagem e ao final, $15 \%$ dos alunos relataram que iniciaram alguma atividade de reciclagem após a implantação do projeto (Tabela 1). A inserção da educação ambiental no currículo escolar promove nos alunos mudanças de atitude no que se refere às questões ambientais (Costa et al. 2015).

Há um consenso entre os estudantes sobre a importância da alimentação saudável, no entanto, 38,6\% deles afirmaram não consumir frequentemente frutas e legumes. Já no final do projeto, $31 \%$ dos estudantes passaram a consumir algum tipo de fruta ou legume. Houve um acréscimo de $48,7 \%$ do total de estudantes que mencionaram que gostariam que a escola fornecesse frutas ou legumes na merenda escolar. Em pesquisa realizada com várias escolas, Coelho \& Bógus (2016) relatam vários depoimentos mostrando que a educação ambiental e a implantação da horta na escola contribuem na mudança dos hábitos alimentares dos estudantes.

$\mathrm{Na}$ temática água e futuro do planeta, $72 \%$ dos estudantes relataram que passaram a fiscalizar o consumo de água e energia em suas residências. 91,4\% mencionaram que acreditam que podem fazer algo para amenizar os efeitos deletérios do homem ao meio ambiente. Em 
Tabela 1. Questionário acerca da consciência ambiental, hábitos diários e alimentares dos estudantes da Escola Francisca Elzika Coelho.

\begin{tabular}{|c|c|c|}
\hline \multirow[t]{2}{*}{ Assunto } & \multicolumn{2}{|c|}{ Quantidade de alunos (\%) } \\
\hline & Início do projeto & Término do projeto \\
\hline \multicolumn{3}{|l|}{ Lixo } \\
\hline Jogam ou jogaram lixo na rua alguma vez & 85,2 & 15,0 \\
\hline Reciclagem & 24,0 & 39,4 \\
\hline \multicolumn{3}{|l|}{ Alimentação saudável } \\
\hline Reconhecem a importância do consumo & 98,0 & 100 \\
\hline Afirmam consumir & 61,4 & 92,4 \\
\hline Gostaria que a escola fornecesse frutas e & 48,1 & 96,8 \\
\hline \multicolumn{3}{|l|}{ Água e futuro do planeta } \\
\hline Consumo consciente & 29,5 & 72,0 \\
\hline $\begin{array}{l}\text { Ações para amenizar os efeitos do } \\
\text { aquecimento global }\end{array}$ & 62,8 & 91,4 \\
\hline \multicolumn{3}{|l|}{ Importância do jardim } \\
\hline Embelezar o local & 100 & 100 \\
\hline Possui plantas em casa & 96 & 100 \\
\hline Manutenção do jardim em casa & 56,4 & 82,9 \\
\hline Conhece plantas ornamentais & 96,4 & 100 \\
\hline
\end{tabular}

projeto similar Santos et al. (2014) relatam mudança comportamental com relação à educação ambiental com maior conscientização nos alunos no tocante ao meio ambiente.

Quando os alunos foram indagados quanto a implantação do jardim, 100\% confirmaram ser uma ideia relevante, tanto para embelezar o local, quanto para amenizar o calor, desses, $96 \%$ dos estudantes relataram ter plantas em casa (Tabela 1). Quanto à manutenção do jardim, 56,4\% afirmaram ajudar nas tarefas diárias. 98\% dos alunos listaram nomes de plantas ornamentais, as plantas mais citadas estão apresentadas na figura 1 . Em relação ao espaço ao final da implantação do projeto, $96 \%$ dos estudantes afirmaram que a escola ficou mais bonita e agradável. Um ambiente escolar agradável e esteticamente interessante traz novas possibilidades de alcançar os objetivos delineados pela escola no que tange à aprendizagem do aluno (Gonçalves \& Souza 2016).

Gradativamente os jardins se constituíam e novas ideias surgiram. Novos atores também se agregavam e a comunidade se viu imbuída na perspectiva do projeto. Nesse interim os próprios alunos, junto com os professores e funcionários da escola, organizaram um evento de conscientização do meio ambiente, realizado no dia da arvore, onde produziram mudas e distribuíram à comunidade. $\mathrm{O}$ conhecimento da realidade é produzido a partir das experiências dos indivíduos e suas trajetórias pessoais. Através da educação ambiental tem-se o desenvolvimento de uma conscientização focada no interesse do aluno pela preservação construída de forma coletiva (Cuba 2010).

Observaram-se nos gestores algumas concepções em que predominam as preocupações com a conservação do meio ambiente e também a concepção integradora que compreende os níveis de complexidade que permeiam a Educação e as questões ambientais, que possa estar conectada com a natureza complexa do ser humano e suas interações em todos os aspectos, tanto físicos, quanto biológico, econômicos, sociais e culturais, ressaltando que esta concepção por ser mais 


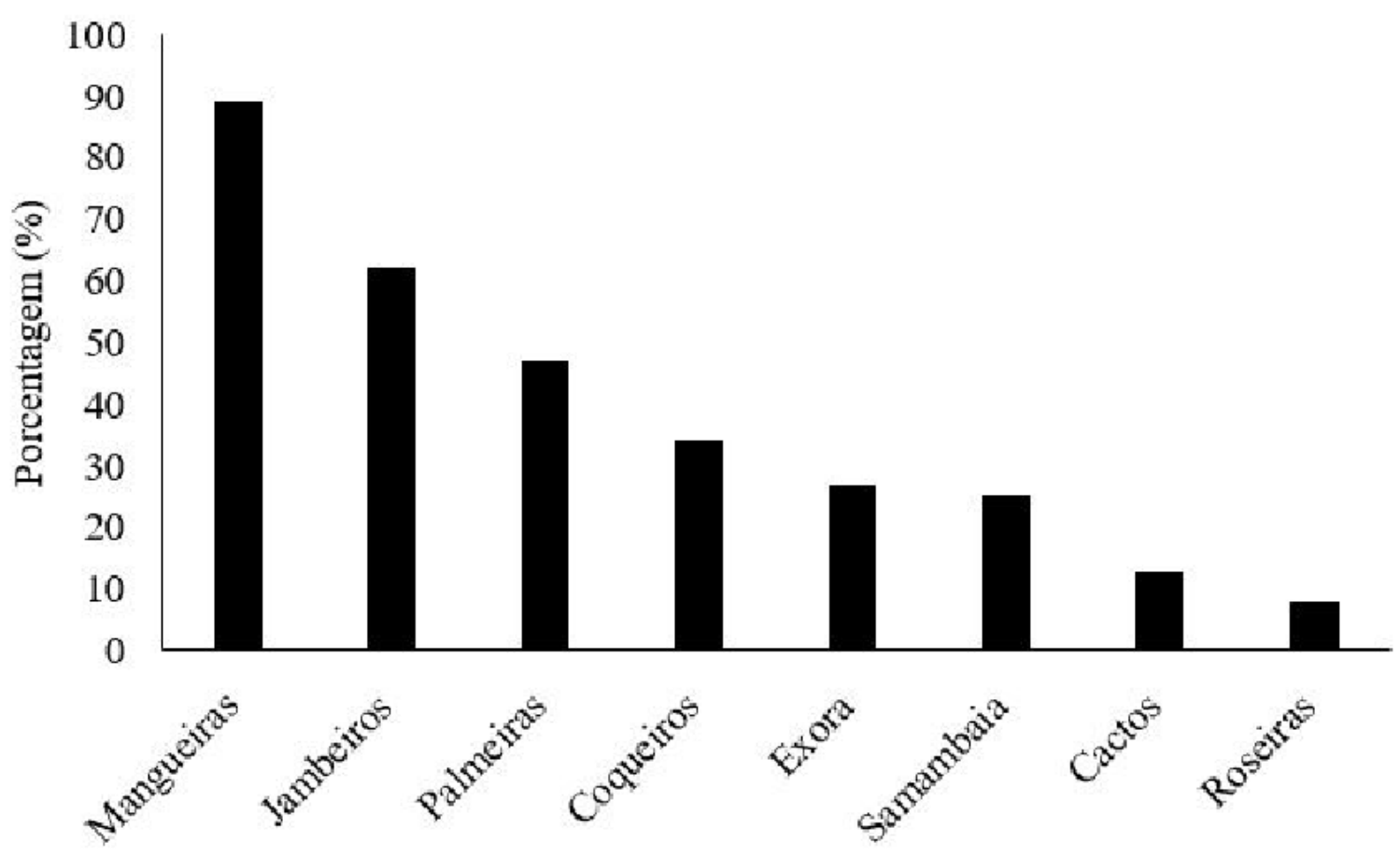

Figura 1. Plantas mais citadas pelos estudantes da Escola Francisca Elzika Coelho como ornamentais.

integradora está pautada numa dimensão que vai além dos recursos naturais, suscitando um agente multiplicador de descobertas e percepções ( Silva et al. 2015).

É consenso mundial à necessidade de conservação e defesa do meio ambiente. Sendo assim, não há outro caminho além da conscientização dos indivíduos para que esta tomada de decisão se multiplique a partir das gerações presentes e passe para as futuras. O trabalho de educação ambiental faz-se vital dentro das escolas, incluindo projetos que envolvam os alunos em sala de aula, tornandoos multiplicadores de atitudes sustentáveis (Santos et al. 2015).

\section{CONSIDERAÇÕES FINAIS}

Os alunos corresponderam às atividades propostas e absorveram a ideia da participação como indivíduos responsáveis pelos lugares que frequentam e habitam, entendendo que o papel principal da educação ambiental é contribuir para que as pessoas adotem uma nova postura com relação a seus próprios lugares.

Portanto, o projeto contribuiu para o ensino e aprendizagem, despertando a consciência ambiental e sustentável, fato que fomenta o educador a buscar informações especificas e novas atividades instigantes ao aluno.

\section{REFERÊNCIAS BIBLIOGRÁFICAS}

Andrade, D.C., Romeiro, A.R. \& Simões, M.S. 2012. From an empty to a full world: a nova natureza da escassez e suas implicações. Economia e Sociedade 21 (3): 695-722.

Bonfim, D.A., Santos, J.O., Sampaio, R.J., Silva Junior, M.F. \& Santos, L.R.C.S. 2015. A interdisciplinaridade, construção do conhecimento e do saber ambiental. Revista Eletrônica do Mestrado de Educação Ambiental 32(1): 344-357.

BRASIL. 1999. Ministério do Meio Ambiente. Política Nacional de Educação Ambiental Lei no 9.795/1999, de 27 de Abril de 1999.

Coelho, D.E.P. \& Bógus, C.M. 2016. Vivências de plantar e comer: a horta escolar como prática educativa, sob a perspectiva dos educadores. Saúde e Sociedade 25(3); 761-771.

Costa, C.A.G., Souza, J.T.A. \& Pereira, D.D. 2015. Horta escolar: alternativa para promover educação ambiental e desenvolvimento sustentável no Cariri Paraibano. Polêmica 15(3): 01-09.

Cuba, M.A. 2010. Educação ambiental nas escolas. Educação, Cultura e Comunicação, 1(2): 23-31.

Czapski, S. \& Trajber, R. 2010. Macrocampo de Educação Ambiental. Brasília: Ministério da 
Educação, 60p.

Gonçalves, F.S. \& Souza, C.Y.V. 2016. Implementação de jardim no ambiente escolar: a experiência da educação ambiental na Escola Estadual Sebastião Vieira Dias no município de Olhos D’Água no Norte de Minas. Revista Intercâmbio 7(1): 368- 374.

Medeiros, A.B., Mendonça, M.J.S.L., Sousa, G.L. \& Oliveira, I.P.A. 2011. Importância da educação ambiental na escola nas séries iniciais. Revista Faculdade Montes Belos, 4(1): 1-17.

Santos, A., Battisti, C.L. \& Battisti, S.A. 2015. Educação ambiental e o processo de ensino/aprendizagem. Instituto Saber de Ciências Integradas - Revista Cientifica 2(3)online.

Santos, M.J.D., Azevedo, T.A.O., Freire, J.L.O., Arnaud, D.K.L. \& Reis, F.L.A.M. 2014. Horta escolar agroecológica: incentivadora da aprendizagem e de mudanças de hábitos alimentares no ensino fundamental. Holos 30(4): 278-290.

Silva, C., Nogueira, M.J.B. \& Pereira, E.M. 2015. Educação ambiental e paisagismo: um olhar dos gestores da educação infantil no Município de Santarém - PA. Revista Exitus 5(2): 138-156. 